OPEN ACCESS

Edited by:

Wanqing Shen,

Université de Lille, France

Reviewed by:

Yifei Sun,

Ruhr University Bochum, Germany

Chuangzhou Wu,

Zhejiang University, China

${ }^{*}$ Correspondence:

Xunyu Mao

191304010006@hhu.edu.cn

Specialty section:

This article was submitted to Interdisciplinary Physics,

a section of the journal

Frontiers in Physics

Received: 30 November 2021

Accepted: 13 December 2021

Published: 06 January 2022

Citation:

He J, Mao X, Zhou Y and Tang $Q$ (2022) Cementation of Sand With

Enzyme-Induced Carbonate Precipitation (EICP) Using Concrete-

Extracted Calcium.

Front. Phys. 9:825356.

doi: 10.3389/fphy.2021.825356

\section{Cementation of Sand With Enzyme-Induced Carbonate Precipitation (EICP) Using Concrete-Extracted Calcium}

\author{
Jia He ${ }^{1}$, Xunyu Mao ${ }^{1 *}$, Yundong Zhou ${ }^{1}$ and Qiang Tang ${ }^{2}$ \\ ${ }^{1}$ Key Laboratory of Geomechanics and Embankment Engineering of Ministry of Education, Hohai University, Nanjing, China, \\ ${ }^{2}$ School of Rail Transit, Soochow University, Suzhou, China
}

Calcium carbonate precipitation and crystallization induced by urease enzyme to solidify soil is known as biocement technology. The uses of waste and cheap materials can make this technology more cost-effective and practical for applications. In this study, calcium ions were obtained by dissolving waste concretes in acidic liquid. Sand columns were treated by enzyme-induced carbonate precipitation (EICP) with either concrete-extracted calcium or reagent calcium for comparison. Compressive strengths, calcium carbonate contents, and microscopic analysis on the treated sand were carried out. It was found that the compressive strength of the former could reach $833 \mathrm{kPa}$ in the dry state and $204 \mathrm{kPa}$ in the wet state after 5 times of EICP treatment, both of which were higher than that of the latter. The calcium carbonate contents could reach 2-3\% after 3-5 times of treatment. Based on the scanning electron microscope (SEM) and X-ray diffractometer (XRD) analyses, the crystal type of calcium carbonate produced in sand was calcite. The comparative results showed that the treatment effect using concrete-extracted calcium was similar or better than that using reagent calcium.

Keywords: waste concrete, calcium ion, enzyme-induced carbonate precipitation (EICP), compressive strength, calcium carbonate content

\section{INTRODUCTION}

Calcium carbonate precipitation induced by the microbial ureolytic process can be utilized as an engineering tool for soil solidification [1-3]. The microbial ureolytic process can be catalyzed by either ureolytic bacteria or urease enzyme, which is named microbial-induced carbonate precipitation (MICP) and enzyme-induced carbonate precipitation (EICP) $[4,5]$. MICP or EICP for soil cementation, or biocement technology, usually requires large amounts of calcium chloride as the calcium source. However, the cost of calcium chloride is relatively high [6]. Therefore, much research has been conducted in order to find alternative calcium sources [7, 8]. Some researchers have studied the feasibility of replacing calcium chloride with soluble calcium sources from domestic waste $[9,10]$. Choi et al. [9] mixed eggshells and vinegar to obtain soluble calcium sources for sand treatment. The results showed that using eggshells as the calcium source for MICP treatment had roughly the same effects compared with that using reagent calcium chloride.

The annual production of urban construction waste in China has exceeded 2 billion tons in recent years. The main component is waste concrete blocks, accounting for $47 \%$ of construction wastes [11]. Most of these waste concretes are directly landfilled or randomly deposited [12]. These waste 
concretes not only occupy large amounts of land but also are difficult to degrade and easily cause secondary pollution. Therefore, it is crucial to find new treatment methods that combine waste resource utilizations with environmental protections. This study proposed a new method of using waste concrete to produce calcium ions for the biocement technology. This method allows for the secondary use of waste concrete and, at the same time, reduces the cost of the calcium source. Sand samples were treated by using the EICP method with either concrete-extracted calcium or reagent calcium chloride. The treatment effects were assessed by compressive strength tests, calcium carbonate content determinations, and microscopic analyses.

\section{EXPERIMENTAL MATERIALS AND METHODS}

\subsection{Experimental Materials \\ 2.1.1 Soybean Urease}

The extraction of crude urease from soybean was carried out as follows [13]: Dry soybeans purchased from the market were ground into powder using a grinder. The soybean powder was dissolved in deionized water at a solid-to-liquid ratio of 1:25. The mixed solution was stirred evenly using a magnetic stirrer. The soybean powder solution was centrifuged at $4^{\circ} \mathrm{C}$ and $3,000 \mathrm{rpm}$ for $15 \mathrm{~min}$. The clean supernatant obtained in this way had relatively high urease activity and was used for soil treatment. The activity of soybean urease solution was $6.66 \mathrm{mM} / \mathrm{min}$, and the initial $\mathrm{pH}$ value was 6.77 at room temperature.

\subsubsection{Experimental Sand}

The sand is China ISO standard sand. The particle size is divided into three levels such as coarse sand $(1.0-2.0 \mathrm{~mm})$, medium sand $(0.50-1.0 \mathrm{~mm})$, and fine sand $(0.08-0.50 \mathrm{~mm})$. The specific gravity is 2.65 . The maximum void ratio is 0.704 , and the void porosity ratio is 0.368 .

\subsubsection{Cementation Solution}

Two kinds of cementation solution were used in the experiment: one was a mixture of equimolar concreteextracted calcium and urea, and the other was a mixture of equimolar reagent calcium chloride and urea of the same concentration. Waste concrete was dissolved in hydrochloric acid to obtain calcium ions. Hydrochloric acid was of industrial grade and contained $31.0 \% \mathrm{HCl}$. In addition to the industrial acid used in this study, the biological method can be considered to produce acid in the future [14]. Although it is not within the scope of this study, this scheme can be tried in the future to further save costs. Waste concrete was concrete blocks of different sizes obtained from the demolition of engineering construction. The concrete was crushed using a grinder and sieved with a standard geotechnical sieve of $1 \mathrm{~mm}$. According to XRF (AXIOS $\mathrm{X}$-ray fluorescence spectrometer in Panakow, the Netherlands), the oxide composition of concrete was determined, and the main components were $\mathrm{SiO}_{2}$ and $\mathrm{CaO}$.
TABLE 1 | Sand sample parameters of different influencing factors.

\begin{tabular}{|c|c|c|}
\hline No. & Number of treatment & $\begin{array}{c}\text { Composition of cementation } \\
\text { fluid }\end{array}$ \\
\hline EC-3 & 3 & Concrete-extracted calcium + urea solution \\
\hline EC-4 & 4 & Concrete-extracted calcium + urea solution \\
\hline EC-5 & 5 & Concrete-extracted calcium + urea solution \\
\hline ER-3 & 3 & Calcium chloride + urea solution \\
\hline ER-4 & 4 & Calcium chloride + urea solution \\
\hline ER-5 & 5 & Calcium chloride + urea solution \\
\hline
\end{tabular}

Notes: E represents enzyme-induced carbonate precipitation (EICP), C represents calcium ion solution extracted from concrete, and $R$ represents calcium chloride solution.

The concrete blocks obtained from the demolition of the project were exposed to air for a long time, and most of them turned into calcium carbonate gradually. Therefore, the process of obtaining calcium ions from waste concretes using $\mathrm{HCl}$ can be expressed as Eq. 1:

$$
\mathrm{CaCO}_{3}+2 \mathrm{HCl} \rightarrow \mathrm{Ca}^{2+}+2 \mathrm{Cl}^{-}+\mathrm{H}_{2} \mathrm{O}+\mathrm{CO}_{2} \uparrow .
$$

In order to obtain the optimal concentration of calcium ion solution, concrete was mixed with $2 \mathrm{M}$ hydrochloric acid. The solid-to-liquid ratio was taken as a variable (1:2, 1:4, 1:6, 1:8), and other factors were kept unchanged. After the reaction, the main component was $\mathrm{SiO}_{2}$, which could be used as roadbed filler. The calcium ion concentration was measured using the EDTA titration method [15]. The results showed that the mixed solution of 1:2 solid-to-liquid ratio produced the highest concentration of calcium ion, which was $0.805 \mathrm{M}$. The $\mathrm{pH}$ of the calcium ion solution was adjusted to 6.5-7.0 with $1 \mathrm{M}$ sodium hydroxide, and the calcium ion solution was centrifuged at $3,000 \mathrm{rpm}$ for $15 \mathrm{~min}$. The supernatant liquid after centrifugation was concrete-extracted calcium, with a concentration of $0.48 \mathrm{M}$. The subsequent experiments were based on the concrete-extracted calcium.

\subsection{Sand Treatment}

Sand columns (100 $\mathrm{mm}$ in height and $50 \mathrm{~mm}$ in diameter) with around $40 \%$ relative density were prepared for the treatment tests. The sand columns were prepared in plexiglass pipes as molds. The pore volume of a sand sample was about $70 \mathrm{ml}$. A geotextile was placed at each end of the sand column as a filter. A peristaltic pump was used to drip soybean urease solution and cementation solution into the sand columns.

The sand treatment procedure was as follows: 1) Dripping the sand specimen with $70 \mathrm{ml}$ of soybean urease solution using a peristaltic pump and leaving for $3 \mathrm{~h}$. 2) Dripping the sand specimen with $70 \mathrm{ml}$ of cementation solution using a peristaltic pump and leaving for $20 \mathrm{~h}$. 3) Repeating steps 1) and 2) for 3-5 times. The entire treatment time took around $24 \mathrm{~h}$. The pumping rate was controlled at $2 \mathrm{ml} / \mathrm{min}$ during the treatment.

\subsection{Experimental Design}

In order to investigate the feasibility of using concreteextracted calcium for biocement technology, sand columns were treated 3-5 times by using the EICP method with either concrete-extracted calcium or reagent calcium chloride for 


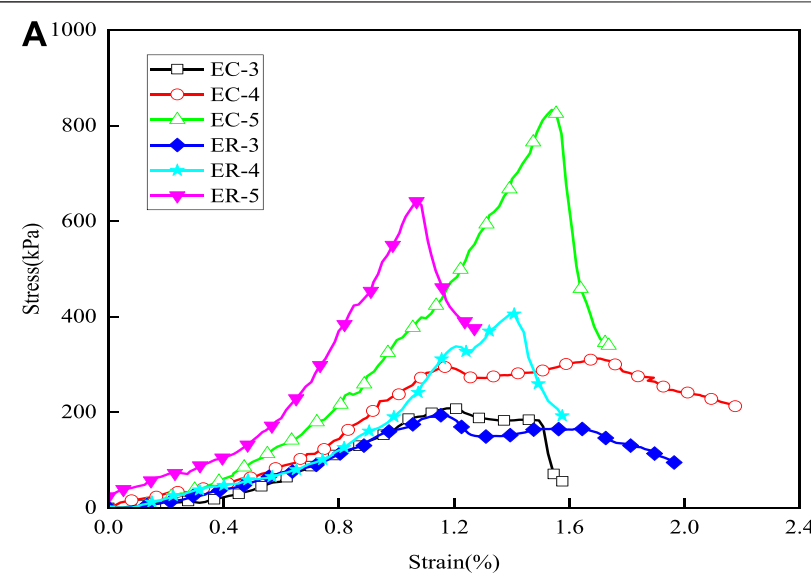

B Dry sand treated by the EICP

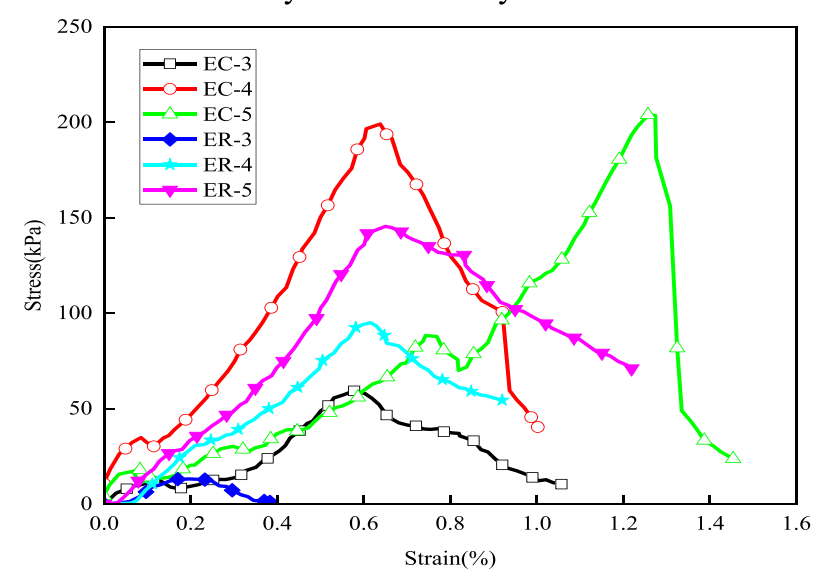

Wet sand treated by the EICP

FIGURE 1 | Stress-strain curve for sand column under compressive strength. (A) Dry sand treated by the EICP; (B) Wet sand treated by the EICP. E represents enzyme-induced carbonate precipitation (EICP), C represents calcium ion solution extracted from concrete, $\mathrm{R}$ represents calcium chloride solution and the numbers represent the number of treatment.

comparison. The test arrangement and the parameters are shown in Table 1. Compressive strength tests, calcium carbonate content determinations, and microscopic analyses on the treated sand were carried out.

\subsection{Measurement Methods}

\subsubsection{Compressive Strength Tests}

The compressive strengths of the treated sand specimens at both the dry and wet states were measured by the unconfined compressive strength test [6]. The unconfined compressive strength test was carried out with the TKA-FWS-1 automatic multi-functional unconfined compressive strength test system (Nanjing Teco Technology Co., LTD.). The sand specimens were rinsed with deionized water for several times to remove the remaining soluble salt. For the test of dry strength, the sand specimens were dried in a $60^{\circ} \mathrm{C}$ oven for $48 \mathrm{~h}$ and cooled naturally to room temperature. For the test of wet strength, the sand specimens were immersed in deionized water at room temperature for $24 \mathrm{~h}$. Before loading, both ends of the specimens were flattened and lubricated. The loading rate of axial displacement in the test was controlled at $1 \mathrm{~mm} / \mathrm{min}$. All the data were automatically recorded using a computer system.

\subsection{2 $\mathrm{CaCO}_{3}$ Content Determinations}

All the sand samples were dried after the compressive strength test. A small amount of sand (around $2 \mathrm{~g}$ each) was taken from the top, middle, and bottom of each sand samples. The small amount sand was separated into two portions and was dissolved in $50 \mathrm{ml}$ of $2 \mathrm{M}$ hydrochloric acid standard solution and deionized water, respectively. After the calcium carbonate reaction was sufficient and no more bubbles were produced, the content of calcium carbonate was determined by using the EDTA titration method [15]. The percentage content of calcium carbonate was calculated according to Eq. 2:

$$
\omega=\frac{c_{a} V_{a}-c_{w} V_{w}}{m} \times 100 \%,
$$

where $\omega$ is the percentage content of calcium carbonate; $c_{\mathrm{a}}$ and $c_{\mathrm{w}}$ are the calcium carbonate content of sample dissolved in acid and water, respectively, mg/L; $V_{\mathrm{a}}$ and $V_{\mathrm{w}}$ are the volume of acid and water, respectively, $\mathrm{ml}$; and $m$ is the sample mass, $\mathrm{g}$.

\subsubsection{Microscopic Analysis}

After the compressive strength tests, material pieces were collected for microscopic analysis. The microstructure was observed by using a scanning electron microscope (SEM), and the crystal types were analyzed using an X-ray diffractometer (XRD). The SEM test was carried out with an FEI Quanta 25 field emission scanning electron microscope. The XRD test was carried out with a Bruker D8 advance, instrument with a scanning angle of $5-90^{\circ}$ at a rate of $5^{\circ}$ per minute.

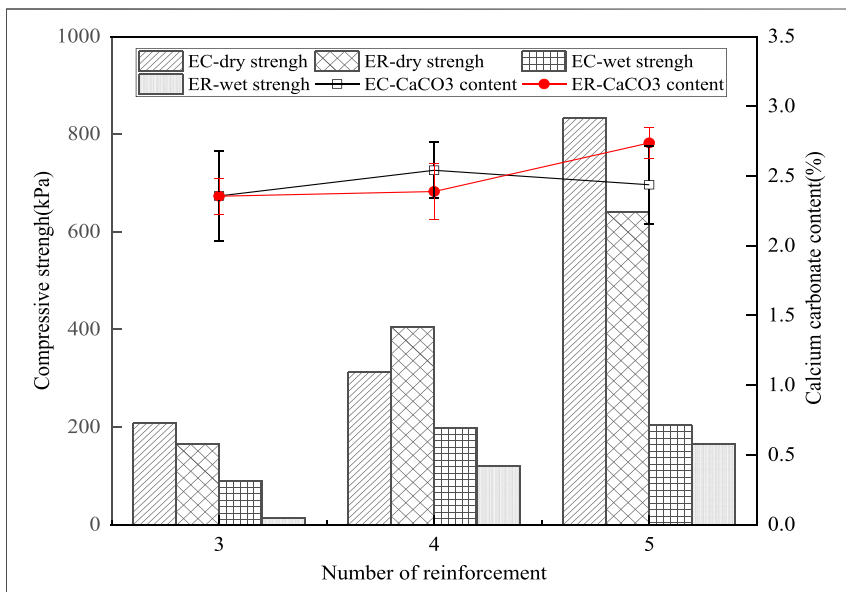

FIGURE 2 | Compressive strength and calcium carbonate content of sand column with different treatment methods and times. 


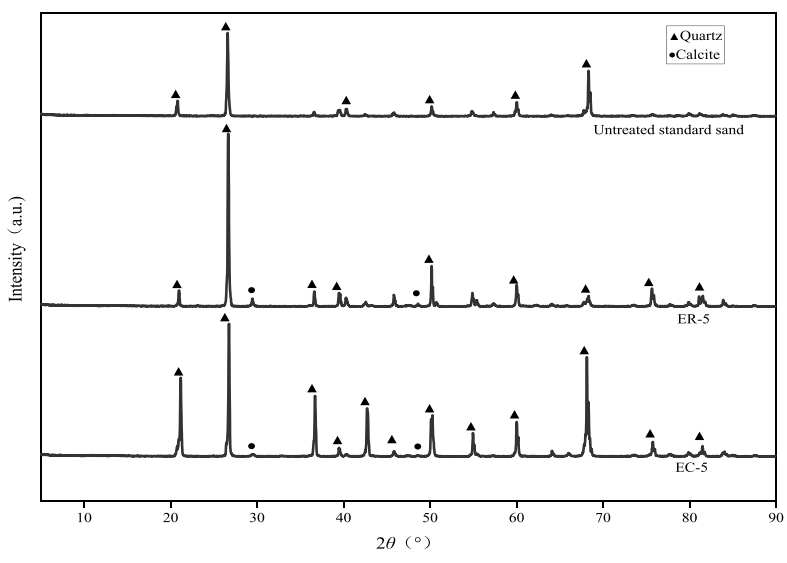

A XRD patterns of sand with different treatment methods

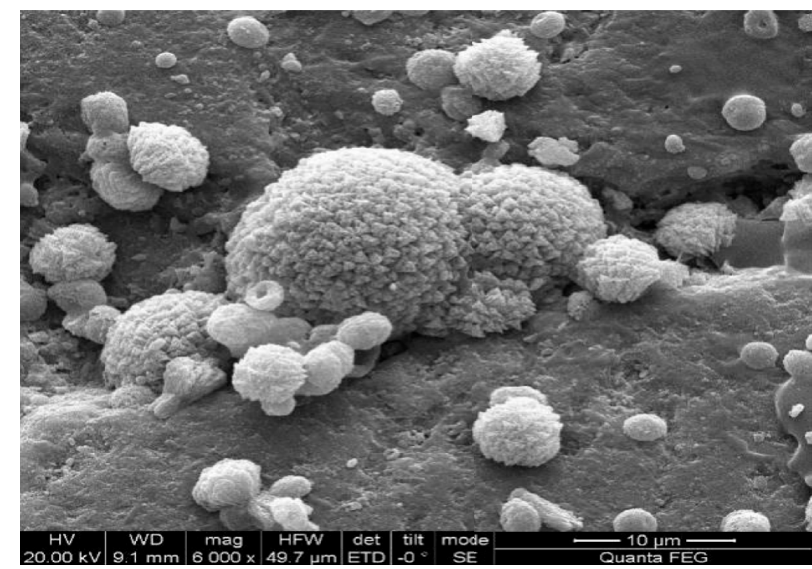

B SEM image of EC-5

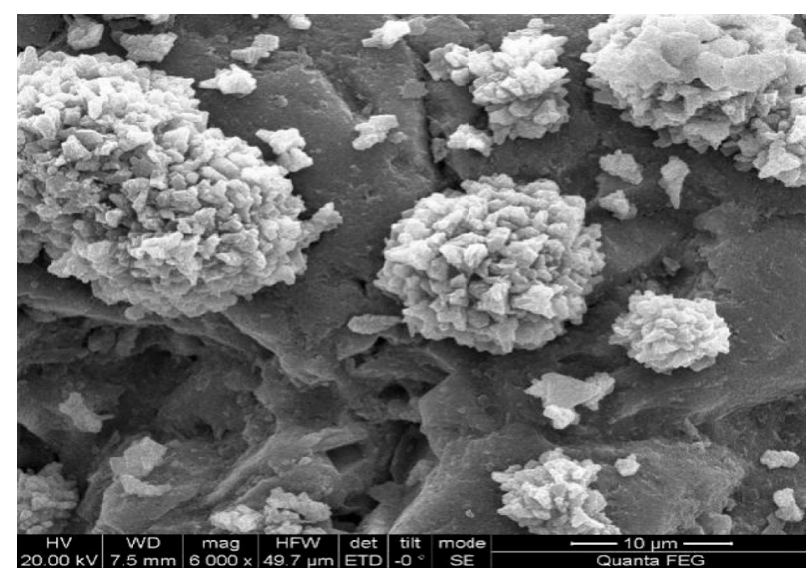

C SEM image of ER-5

FIGURE $3 \mid X R D$ and SEM images of sand treated with different calcium sources. (A) XRD patterns of sand with different treatment methods; (B) SEM image of EC-5; (C) SEM image of ER-5. E represents enzyme-induced carbonate precipitation (EICP), C represents calcium ion solution extracted from concrete, $\mathrm{R}$ represents calcium chloride solution and 5 represents the number of treatment.

\section{TEST RESULTS}

\subsection{Compressive Strength}

The stress-strain curves of the sand specimens in the dry and wet states are shown in Figure 1. It can be seen that stresses of all specimens decrease rapidly after reaching the peak values. With the increase in treatment times, the peak value of the axial stress in each specimen increased.

Figure 2 shows the compressive strength and average calcium carbonate content of sand column treated with the EICP process for different times with different calcium sources. Overall, both dry and wet strengths increased with the increase in treatment times. The dry strength of sand treated 5 times was 3- to 4 -fold higher than that treated 3 times. The wet strength of sand treated 5 times was twice higher than that treated 3 times. Between the sand specimens treated with concrete-extracted calcium and reagent calcium, there was no significant difference in dry strengths after three and four treatments, and the dry strength of the former was greater than that of the latter at 5 times of treatments. The wet strength of both types of specimens was relatively low compared with the dry state. The dry strength of the former could reach $833 \mathrm{kPa}$, and the wet strength could reach $204 \mathrm{kPa}$ after 5 times of treatments. In general, sand specimens treated with concrete-extracted calcium and reagent calcium had no significant difference in strength at both the dry and wet states.

\section{2 $\mathrm{CaCO}_{3}$ Content}

As can be seen in Figure 2, the calcium carbonate contents were in the range of $2-3 \%$ and increased roughly with more treatment times. There was no significant difference in calcium carbonate contents between the specimens treated with concrete-extracted calcium and reagent calcium. The relationship between the treatment times and calcium carbonate contents implied that the treatment efficiency (i.e., calcium carbonate produced in each treatment) reduced with more treatment times. It could be due to the decreasing permeability with more treatment times. It could also be found that the compressive strength of the specimen was positively correlated with the amount of calcium carbonate generated.

\subsection{Microscopic Analysis}

Figure 3 is the XRD and SEM images of untreated sand and sand treated with different calcium sources. As can be seen from the XRD image (Figure 3A), the untreated sand was purely quartz, and treated specimens were quartz and calcite. However, minerals formed by elements such as $\mathrm{Al}$ and $\mathrm{Mg}$ in concrete are not shown in the figure due to their low content. There are several crystal forms of calcium carbonate such as calcite, vaterite, and aragonite [16]. Calcite is the most stable form of calcium carbonate and is found to be the dominating form when produced in the MICP process. The results in this study also proved that when using the concrete extract as the calcium source in the EICP process, the produced calcium carbonate was also calcite. The calcium carbonate produced from concrete-extracted calcium (Figure 3B) was mostly spherical aggregates formed by spherical or triangular pyramidal aggregates, and a small part was small individual spheres. The calcium carbonate produced from reagent calcium chloride (Figure 3C) was mostly clumped aggregates formed by irregular polyhedral blocks, and a small part was small individual blocks. 


\subsection{Cost Analysis}

According to the current market price, the material cost of treating $1 \mathrm{~m}^{3}$ sand with concrete-extracted calcium is around $255 \mathrm{CNY}$. The material cost of treating $1 \mathrm{~m}^{3}$ sand with reagent calcium chloride is around $340 \mathrm{CNY}$. However, the costs mentioned here are based on the market prices in 2021 in China and may vary over time and regions.

\section{CONCLUSION}

In this study, a new method of using waste concrete for EICP sand treatment is proposed. The concrete-extracted calcium and reagent chloride solution are used to treat sand columns, respectively. The treated sand specimens are assessed by compressive strength tests, calcium carbonate content determinations, and microstructure analyses. The main conclusions are as follows:

(1) The compressive strength of the sand column treated by concrete-extracted calcium and reagent calcium chloride has no significant difference in both dry and wet states, indicating the effectiveness of using waste concrete for calcium extraction and the EICP treatment.

(2) The calcium carbonate contents treated by using the EICP method with concrete extracted calcium after 3-5 times are

\section{REFERENCES}

1. Almajed A, Khodadadi Tirkolaei H, Kavazanjian E. Baseline Investigation on Enzyme-Induced Calcium Carbonate Precipitation. J Geotech Geoenviron Eng (2018) 144(11):04018081. doi:10.1061/(asce)gt.1943-5606.0001973

2. Qian CX, Wang AH, Wang X. Advances of Soil Improvement with Bio-Grouting. Rock Soil Mech (2015) 36(06):1537-48. doi:10.16285/j.rsm.2015.06.003

3. Wu LY, Miao LC, Sun XH, Chen RF, Wang CC. Experimental Study on Sand Solidification Using Plant-Derived Urease-Induced Calcium Carbonate Precipitation. Chin J. Geot. Eng. (2020) 42(4):714-20. doi:10.11779/CJGE202004014

4. He J, Chu J, Liu HL, Gao YF, Li B. Research Advances in Biogeotechnologies. Chin J. Geot. Eng. (2016) 38(4):643-53. doi:10.11779/CJGE201604008

5. Cui MJ, Lai HJ, Hoang T, Chu J. One-phase-low-pH Enzyme Induced Carbonate Precipitation (EICP) Method for Soil Improvement. Acta Geotech. (2021) 16:481-9. doi:10.1007/s11440-020-01043-2

6. Liu L, Liu H, Xiao Y, Chu J, Xiao P, Wang Y. Biocementation of Calcareous Sand Using Soluble Calcium Derived from Calcareous Sand. Bull Eng Geol Environ (2018) 77:1781-91. doi:10.1007/s0064-017-1106-4

7. Liang SH, Niu JG, Fang CX, Dai J, Yin YM, Liu YJ. Experimental Study on the Effect of Nutrient Solution Calcium Sources on Bio-Cemented Sand. J Disas Prev Mitig Eng (2018) 38(05):781-6. doi:10.13409/j.cnki.jdpme.2018.05.002

8. Gorospe CM, Han SH, Kim SG, Park JY, Kang CH, Jeong JH, et al. Effects of Different Calcium Salts on Calcium Carbonate crystal Formation by Sporosarcina Pasteurii KCTC 3558. Biotechnol Bioproc E (2013) 18:903-8. doi:10.1007/s12257013-0030-0

9. Choi SG, Wu S, Chu J. Biocementation for Sand Using an Eggshell as Calcium Source. J Geotech Geoenviron Eng (2016) 142(10):06016010. doi:10.1061/ (ASCE)GT.1943-5606.0001534

10. Liang S, Chen J, Niu J, Gong X, Feng D. Using Recycled Calcium Sources to Solidify sandy Soil through Microbial Induced Carbonate Precipitation. Mar Georesources Geotechnology (2020) 38(4):393-9. doi:10.1080/1064119X.2019.1575939

11. Sun YLQ. Study on Mechanical Performance of Recycled Aggregate Concrete Compoents Containing Waste Concrete and Bricks. (Dissertation). Hangzhou: Zhejiang University (2021). in the range of $2-3 \%$. There is no significant difference in the calcium carbonate contents between the specimens treated with concrete-extracted calcium and calcium chloride.

(3) The calcium carbonate crystal produced from concreteextracted calcium in the sand treatment process is calcite, which is the most stable form of calcium carbonate.

\section{DATA AVAILABILITY STATEMENT}

The original contributions presented in the study are included in the article/Supplementary Material; further inquiries can be directed to the corresponding author.

\section{AUTHOR CONTRIBUTIONS}

XM wrote the article. All authors made analysis and discussed the contents.

\section{FUNDING}

This study was supported by research grants (No. 52078188, 51979088) from the National Natural Science Foundation of China.

12. Cheng HL, Liu GQ, Yang FH, Hao LW. Influence of Recycled Waste Concrete Aggregate and Mineral Admixtures on Durability of GRC. $J$ Build Mater (2018) 21(03):490-6+510. doi:10.3969/j.issn.10079629.2018.03.023

13. Gao Y, He J, Tang X, Chu J. Calcium Carbonate Precipitation Catalyzed by Soybean Urease as an Improvement Method for fine-grained Soil. Soils and Foundations (2019) 59(5):1631-7. doi:10.1016/j.sandf.2019.03.014

14. Liang Y, Zhao X, Chi Z, Rover M, Johnston P, Brown R, et al. Utilization of Acetic Acid-Rich Pyrolytic Bio-Oil by Microalga Chlamydomonas Reinhardtii: Reducing Bio-Oil Toxicity and Enhancing Algal Toxicity Tolerance. Bioresour Tech (2013) 133:500-6. doi:10.1016/j.biortech.2013.01.134

15. Water Quality. Water Quality-Determination of Calcium-EDTA Titrimetric Method: GB/T 7476-1987. Beijing: China Standard Press. (1987).

16. Liu Y. Experimental Study on Wind-Breaking and Sand-Fixing Using Soybean Urease Induced Carbonate Precipitation. dissertation. Nanjing: Hohai University (2020).

Conflict of Interest: The authors declare that the research was conducted in the absence of any commercial or financial relationships that could be construed as a potential conflict of interest.

Publisher's Note: All claims expressed in this article are solely those of the authors and do not necessarily represent those of their affiliated organizations, or those of the publisher, the editors, and the reviewers. Any product that may be evaluated in this article, or claim that may be made by its manufacturer, is not guaranteed or endorsed by the publisher.

Copyright (c) $2022 \mathrm{He}, \mathrm{Mao}$, Zhou and Tang. This is an open-access article distributed under the terms of the Creative Commons Attribution License (CC $B Y)$. The use, distribution or reproduction in other forums is permitted, provided the original author(s) and the copyright owner(s) are credited and that the original publication in this journal is cited, in accordance with accepted academic practice. No use, distribution or reproduction is permitted which does not comply with these terms. 